\title{
The Growth of Yeast and Fungi, the Formation of $\beta$-Glucan, and the Antibacterial Activities during Soybean Fermentation in Producing Tempeh
}

\author{
Samsul Rizal (D), Maria Erna Kustyawati (D, Murhadi, and Udin Hasanudin \\ Department of Agricultural Product Technology, Faculty of Agriculture, University of Lampung, Jalan Sumantri Brojonegoro No. 1 \\ Bandar Lampung, Lampung 35145 ., Indonesia
}

Correspondence should be addressed to Samsul Rizal; samsul.rizal@fp.unila.ac.id and Maria Erna Kustyawati; maria.erna@fp.unila.ac.id

Received 12 November 2020; Revised 3 January 2021; Accepted 12 January 2021; Published 27 January 2021

Academic Editor: Dimitrios Tsaltas

Copyright (C) 2021 Samsul Rizal et al. This is an open access article distributed under the Creative Commons Attribution License, which permits unrestricted use, distribution, and reproduction in any medium, provided the original work is properly cited.

Generally, the microorganism involved in soybean fermentation for the production of tempeh is Rhizopus oligosporus. However, Saccharomyces cerevisiae, a type of $\beta$-glucan-producing yeast, is known to be present and grow in the fermentation process. This study was aimed at investigating yeast and fungal growth dynamics, $\beta$-glucan formation, and antibacterial activity against Escherichia coli during the fermentation after adding S. cerevisiae as an inoculum. The Randomized Complete Block Design (RCBD) was applied with two treatments and three repetitions. Three types of starter culture were S. cerevisiae, R. oligosporus, and the combination of both. The second treatment was fermentation time at room temperature $\left(30 \pm 2^{\circ} \mathrm{C}\right)$ for $0,8,16,24,32$, and 40 hours. The dynamics were observed every eight hours. The obtained data were tested using Tukey's Honestly Significant Difference (HSD) test. The results indicated that yeast grew during this process from a single S. cerevisiae culture and a mixture of $R$. oligosporus and S. cerevisiae, but not from R. oligosporus alone. The yeast grew during and until the end of fermentation and decreased after 32 hours in the mixed cultures. The $\beta$-glucan formed in tempeh with all types of inoculum, but the antimicrobial activity against $E$. coli increased with fermentation time and was significantly different between treatments. The highest $\beta$-glucan content and antibacterial activity of tempeh are from the mixed culture. In conclusion, the addition of $S$. cerevisiae and $R$. oligosporus in soybean fermentation produced tempeh with the highest $\beta$-glucan content and antibacterial activity against $E$. coli. The presence of $\beta$-glucans suggests higher health benefits of tempeh.

\section{Introduction}

Tempeh is a traditional Indonesian fermented food produced from soybeans by using Rhizopus sp. This healthy functional food is due to bioactive compounds such as isoflavones. It has nutritional advantages, unique texture, and pleasant flavors [1]. The quality of tempeh depends on the raw material and type of inoculum or starter culture used. The kind of inoculum plays a vital role in making tempeh because it affects tempeh's quality.

Generally, tempeh uses an inoculum containing $R$. oligosporus [2]. Other important microorganisms involved in fermenting soybeans to form tempeh are $R$. oryzae and $R$. stolonifer [3]. All three microorganisms ferment soybeans into tempeh. Rhizopus oligosporus retains most of the nutrients in soybeans and increases protein digestibility [4]. R. oligosporus synthesizes more protease enzyme, whereas $R$. oryzae favors the $\alpha$-amylase enzyme [5].

Besides $R$. oligosporus, yeast and bacteria were also involved during fermentation and significantly contributed to producing functional metabolites [6]. Seumahu et al. [7] and Efriwati et al. [8] found lactic acid bacteria (LAB) and yeast in tempeh. A kind of yeast found in tempeh fermentation was Saccharomyces cerevisiae [9], which is known as a $\beta$ glucan-producing microorganism [10].

In this study, S. cerevisiae was added intentionally to the soybean fermentation process to produce tempeh with high $\beta$-glucan content and, therefore, to improve the functional 
properties as a healthy food. The $S$. cerevisiae cell wall is composed of $\beta$-(1,3)- and $\beta$-(1,6)-glucan, mannan, chitin (1-2\%), and mannoproteins, comprising about $20-30 \%$ of the dry weight of the cell wall [11]. $\beta$-Glucan is a polysaccharide that has health benefits, for example, as a biological response modifier [12] and as an antibiotic against bacteria, fungi, viruses, and parasites [13].

The yeast could grow alongside fungi during soybean fermentation when a carbon source was added, thus resulting in $\beta$-glucans in the tempeh produced [14]. In this study, S. cerevisiae was added to the soybean fermentation without carbon sources. It is important to test whether the addition of fungi without any carbon source in the fermentation of tempeh can provide yeast growth and the formation of $\beta$-glucans in tempeh. Also, the presence of $\beta$-glucan due to yeast addition might add health benefits, including antibacterial activity. Therefore, this study was aimed at observing the effect of $S$. cerevisiae addition to the growth dynamics of yeast and fungi, the $\beta$-glucan formation, and the antibacterial activities against Escherichia coli during soybean fermentation to produce tempeh.

\section{Materials and Methods}

This study used pure cultures of R. oligosporus FNCC 6010, S. cerevisiae FNCC 3012, and E. coli obtained from the UGM Inter-University Food and Nutrition Center, soybeans (brand "Soybean USA No. 1"), Nutrient Broth (NB), Nutrient Agar (NA), Malt Extract Agar (MEA), and Potato Dextrose Agar (PDA). The experimental analysis employed a Factorial Randomized Complete Block Design with three repetitions. The first factor was the three inoculum treatments: S. cerevisiae, $R$. oligosporus, and the mix of both microorganisms. The second factor was the fermentation time of six levels: $0,8,16,24,32$, and 40 hours. During fermentation time, we observed the microbial population, the $\beta$-glucan content, and the antibacterial activity toward E. coli in $(0,8,16,24,32$, and 40 hours) of fermentation time. The obtained data were tested using Tukey's Honestly Significant Difference (HSD) test.

2.1. Preparation of S. cerevisiae Culture. The S. cerevisiae was cultured in a sterile Malt Extract Agar (MEA) medium using a sterilized inoculating loop needle with a scratchplate, then incubated for 24 to 48 hours at $28^{\circ} \mathrm{C}$ to form colonies. The colonies were harvested by adding 5 or $10 \mathrm{~mL}$ of distilled water into the plate disc. The fungal cells were harvested and poured into a $50 \mathrm{~mL}$ centrifuge tube. The tube was weighed and spun at $3000 \mathrm{rpm}$ for 10 minutes to obtain a separate solid from the supernatant. The supernatant was discarded, and the remaining solids were diluted with 25 to $30 \mathrm{~mL}$ of distilled water. The cells were transferred into a test tube containing $9 \mathrm{~mL}$ of physiological saline solution and then homogenized using a vortex. The number of cells was calculated using a hemocytometer. The required concentration was $10^{7}$ cells $/ \mathrm{mL}$.

2.2. Preparation of R. oligosporus Culture. R. oligosporus from a tilted agar was cultured in a sterile medium of Potato Dex- trose Agar (PDA) using a sterilized inoculating loop needle and a scratchplate. The mold was incubated for five to seven days at 30 to $35^{\circ} \mathrm{C}$ to obtain pure colonies, harvested in the same way as the $S$. cerevisiae. The required concentration was $10^{5}$ cells $/ \mathrm{mL}, 100$ times less than S. cerevisiae.

2.3. Production of Soybean Tempeh. $300 \mathrm{~g}$ of soybeans was immersed in water at room temperature $\left(30 \pm 2^{\circ} \mathrm{C}\right)$ overnight, then boiled in water with a ratio of $1: 3$ soybean to water for 30 minutes, drained, cooled to ambient temperature, and inoculated with starters.

Three separate $100 \mathrm{~g}$ samples of boiled soybeans received these inoculums:

(1) $1 \mathrm{~mL}$ suspension of $10^{5}$ spores/mL of $R$. oligosporus

(2) $1 \mathrm{~mL}$ suspension of $10^{7}$ cells $/ \mathrm{mL}$ of $S$. cerevisiae

(3) $1 \mathrm{~mL}$ suspension of $10^{5}$ spores/mL of $R$. oligosporus $+1 \mathrm{~mL}$ suspension of $10^{7}$ cells/mL of $S$. cerevisiae

The samples were packaged in plastics perforated for ventilation, then incubated at $32^{\circ} \mathrm{C}$ for 40 hours, and observed every eight hours.

2.4. Enumeration of Microorganisms. The microorganisms were enumerated by culturing on PDA for the fungi and MEA for the yeast. Immediately at 0 hours, then at 8 , $16,24,32$, and 40 hours, consecutively, each tempeh was sampled and diluted following the method of Kustyawati [20]. Ten grams of the sample and $90 \mathrm{~mL}$ of peptone water were homogenized with a stomacher paddle blender for five minutes, then diluted into the concentration series. One $\mathrm{mL}$ of each dilution was planted with the appropriate surface plate calculation method on the media. Incubation continued for 24 to 48 hours at $32^{\circ} \mathrm{C}$ to grow fungi and $30^{\circ} \mathrm{C}$ to grow yeast.

2.5. Analysis of $\beta$-Glucan. The $\beta$-glucan formation was analyzed every eight hours during fermentation following Rizal et al. [14]. One gram of the sample and $30 \mathrm{~mL}$ of $0.7 \mathrm{~N} \mathrm{NaOH}$ were hydrolyzed for six hours at $75^{\circ} \mathrm{C}$ and centrifuged at $10,000 \mathrm{rpm}$ at $25^{\circ} \mathrm{C}$ for 30 minutes. The supernatant was removed, and the residue was washed with $30 \mathrm{~mL}$ of $0.5 \mathrm{M}$ acetic acid solution and centrifuged again at 10,000 rpm and $25^{\circ} \mathrm{C}$ for 30 minutes. This process was repeated three times. The precipitated material was washed twice with $20 \mathrm{~mL}$ of water and centrifuged at 5,000 rpm for 10 minutes.

The residue with $20 \mathrm{~mL}$ of ethanol was centrifuged at $5,000 \mathrm{rpm}$ for 10 minutes, resulting in wet $\beta$-glucan (crude). This biomass was dehydrated at a $45^{\circ} \mathrm{C}$ oven for 24 hours and weighed to obtain the dry weight of $\beta$-glucan (crude). The dry residue with $4 \mathrm{~mL}$ of $1 \mathrm{M} \mathrm{NaOH}$ was left for one hour. Afterward, the sample was diluted with $10 \mathrm{~mL}$ of sterile distilled water and shaken with an orbital shaker. The sample was added with $2 \mathrm{~mL}$ of $\mathrm{Pb}$ acetate and left to stand for 30 minutes. Finally, one gram of sodium oxalate clears the solution, and two $\mathrm{mL}$ of it with $0.5 \mathrm{~mL}$ of phenol $5 \%$ and $2.5 \mathrm{~mL}$ of sulfuric acid $5 \mathrm{~N}$ was tested using a sugar-free content spectrophotometer under $490 \AA$ A wavelength. 


\subsection{Assessment of Antibacterial Activities}

2.6.1. Preparation of E. coli. Pure E. coli $(20 \mu \mathrm{L})$ were grown on Mac Conkey Agar (MCA) media and incubated at $37^{\circ} \mathrm{C}$ for 24 hours. The bacteria were taken with an inoculating loop needle from the MCA media and put into the Nutrient Broth (NB) media and incubated at $37^{\circ} \mathrm{C}$ for 24 hours. One $\mathrm{mL}$ of the bacterium was diluted in $9 \mathrm{~mL}$ of physiological $\mathrm{NaCl} 0.85 \%$ in a sterile test tube and homogenized using a vortex for 15 seconds.

2.6.2. Antibacterial Testing. $100 \mu \mathrm{L}$ of the bacteria was poured evenly on the surface of the NA medium using the spread plate method and let dry. A $2 \mathrm{~g}$ sample from each treatment was dissolved in $8 \mathrm{~mL}$ of sterile distilled water. A paper disc (5.5 mm diameter) was inserted into each of these treatments and allowed to stand for 10 minutes. After that, the paper disc was placed on the NA medium's surface containing the target bacteria, then incubated at $37^{\circ} \mathrm{C}$ for 24 hours. After 24 hours, the inhibitory area diameter formed surrounding the paper disc was measured using a slide. The sample's antibacterial activity was expressed by the inhibitory zone diameter as a clear area around the disc. The antibacterial testing was carried out in 3 repetitions.

\section{Results and Discussion}

3.1. Growth of Yeast and Fungi during Fermentation. Figure 1 shows the growth of yeast and fungi in various types of cultures used in the fermentation of soybeans to tempeh. During fermentation of soybeans with only the R. oligosporus culture, there was no increase in the amount of yeast (Figure 1(a)), whereas during fermentation using only $S$. cerevisiae alone, the fungus did not grow (Figure 1(b)). In contrast, both fungi and yeast reproduce well during the fermentation of soybeans with mixed cultures of $R$. oligosporus and S. cerevisiae (Figure 1(c)).

Figure 1(a) shows the growth curve of S. cerevisiae in tempeh inoculated with only $S$. cerevisiae. The adaptation phase occurred in zero up to 8 hours of fermentation with a population of $10^{7} \mathrm{CFU} / g$. For comparison, Sugoro and Pikoli [15] stated that the adaptation phase in a modified $1 \%$ tapioca solution medium containing $10.21 \%$ glucose was at the sixth hour of fermentation. Kusmiati et al. [16] reported that in media with glucose as a carbon source, this fungus' adaptation phase was four hours. On the YNB medium containing $30 \%$ of glucose, Ishmayana et al. [17] had it at six hours of fermentation. Our adaptation phase in this experiment was delayed than those of Sugoro and Pikoli [15], Kusmiati et al. [16], and Ishmayana et al. [17] because there was no carbon source on the substrate as needed for the growth during fermentation.

Figure 1(a) also shows that after eight hours of fermentation, the yeast experiences a sharp increase in the number of cells from $1.73 \times 10^{8} \mathrm{CFU} / g$ at 16 hours of fermentation to $3.33 \times 10^{9} \mathrm{CFU} / \mathrm{g}$ at 24 hours of fermentation. This increase indicated that yeast (S. cerevisiae) entered an exponential phase after eight hours. Kavanagh [18] stated that in the exponential phase, the yeast reproduced by budding. The maximum specific growth rate $\left(\mu_{\max }\right)$ of yeast is 0.012 cells/hour based on the exponential phase. Furthermore, the yeast experienced a stationary phase from 24 hours to 40 hours, with a population of $4.82 \times 10^{9} \mathrm{CFU} / \mathrm{g}$. The death phase of yeast appeared to occur after 40 hours of fermentation time.

Yeast can grow during the fermentation process of soybeans inoculated with only S. cerevisiae even though tempeh is not formed. S. cerevisiae as a sole culture (without the addition of the primary tempeh fungus) in 40 hours of fermentation does not form tempeh (Figure 2(a)). To make tempeh, an inoculum is needed. Otherwise, the soybeans will simply decay. S. cerevisiae increases, but there is no presence of $R$. oligosporus unless it is inoculated. This result is in line with Wahono et al. [19], who reported that during the fermentation of sorghum seeds in bioethanol production, there was an increase in the growth rate of $S$. cerevisiae. Yeast can grow by utilizing the nutrients present in the soybean substrate. According to Kustyawati (2010), almost all foods provide sufficient nutrition to support yeast growth.

Figure 1(b) shows no growth of yeast during tempeh fermentation with $R$. oligosporus as a single inoculum. Unless $S$. cerevisiae is inoculated, there will be no yeast growth. In soybean fermentation using $R$. oligosporus as a single culture, there was no yeast growth, but tempeh was still formed due to hyphae from $R$. oligosporus (Figure 2(b)). This result was in line with Kustyawati [20], which stated that yeast was not found during tempeh fermentation using $R$. oligosporus. Thus, this study revealed that yeast in tempeh could only be seen when the fermented soybeans were added with yeast.

The growth dynamics of yeast and the appearance of soybeans during tempeh fermentation inoculated with the mixed culture of $R$. oligosporus and $S$. cerevisiae are presented in Figures 1(c) and 2(c). Figure 1(c) shows that yeast's adaptation phase occurs between zero and eight hours while the adaptation phase of fungi occurs between zero and 16 hours. In this sample, both microorganisms grew simultaneously and continued increasing until the end of the experiment at 40 hours of fermentation. The appearance of tempeh inoculated with mixed cultures of $R$. oligosporus and $S$. cerevisiae during fermentation showed that there was no significant fungal growth from 0 to 16 hours of fermentation and soybeans were still intact (Figure 2(c)). After 16 hours of fermentation, fungi entered the exponential growth phase marked by an increase in the number of $R$. oligosporus spores up to $7.67 \times 10^{6} \mathrm{CFU} / \mathrm{g}$ at 24 hours of fermentation time and 2.73 $\times 10^{7} \mathrm{CFU} / g$ at 32 hours of fermentation time.

This growth pattern is in line with the growth pattern of $S$. boulardii, which was inoculated together with $R$. oligosporus for tempeh fermentation in a study conducted by Kustyawati [20]. The yeast growth pattern in this treatment was similar to that of soybeans inoculated with $S$. cerevisiae alone. It indicates that $S$. cerevisiae utilizes the nutrients present in soybeans for growth, and there is a mutually beneficial symbiosis between $R$. oligosporus and S. cerevisiae during fermentation. According to Kustyawati [20], there may be a mutually helpful symbiosis in nutrient availability between $R$. oligosporus and S. cerevisiae during tempeh fermentation 


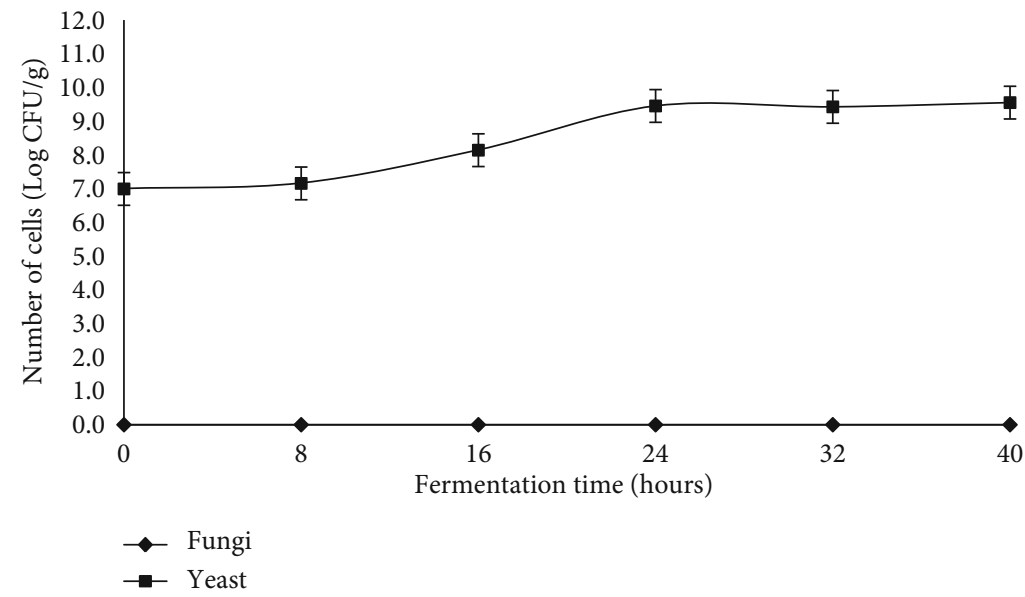

(a)

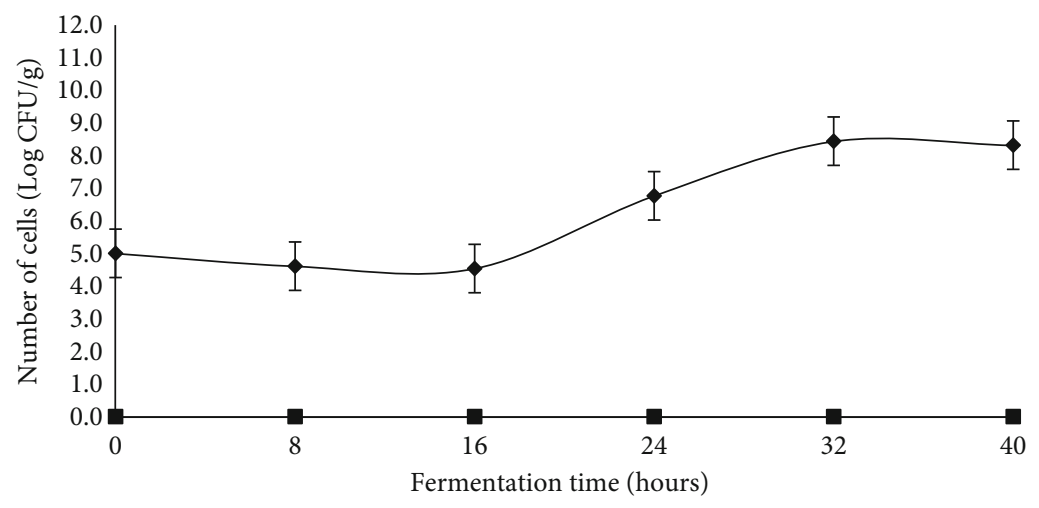

- Fungi

$\rightarrow$ Yeast

(b)

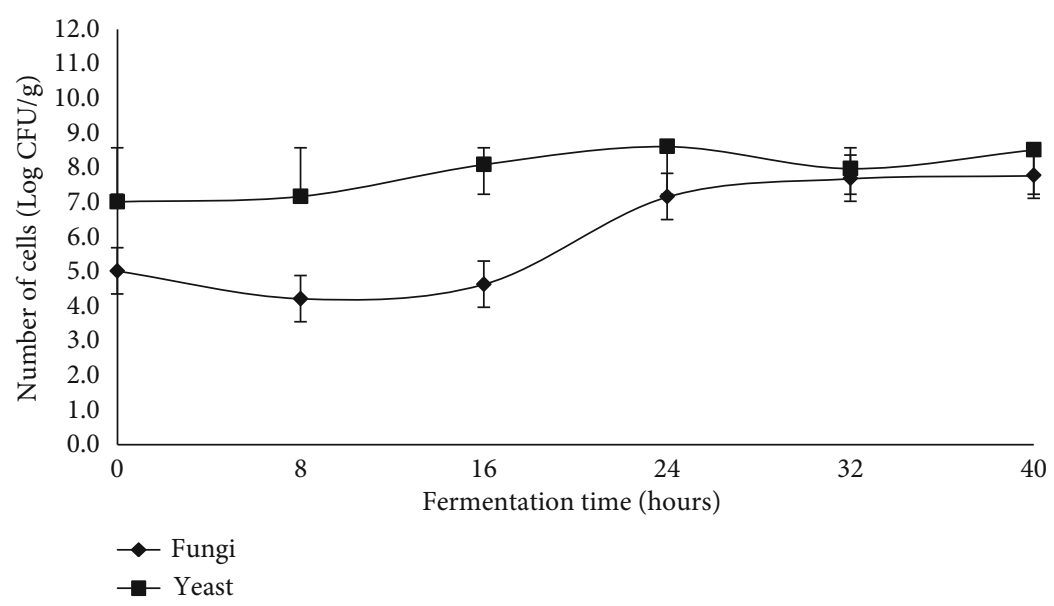

(c)

FIgURE 1: The growth curves of yeast and fungi during soybean fermentation inoculated with a single culture of S. cerevisiae (a), a single culture of R. oligosporus (b), and a mixed culture of both microorganisms (c).

to achieve synergistic growth. Rhizopus oligosporus breaks down carbohydrate, fat, and protein into simple forms, and S. cerevisiae absorbs the elements $\mathrm{C}, \mathrm{H}, \mathrm{O}$, and $\mathrm{N}$ from them. In turn, enzymatic activity by $S$. cerevisiae benefits $R$. oligosporus.
3.2. Formation of $\beta$-Glucan. $\beta$-Glucans are polysaccharides that have several health benefits, including as an antimicrobial [13], which can inhibit the growth of bacteria and viruses. All types of starter culture increased the $\beta$-glucan content of tempeh over time (Figure 3 ). The $\beta$-glucan 

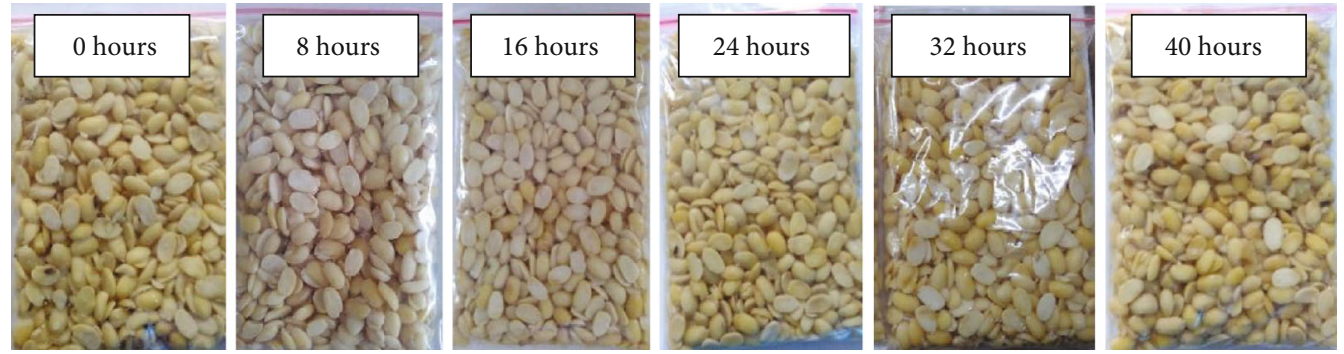

(a)
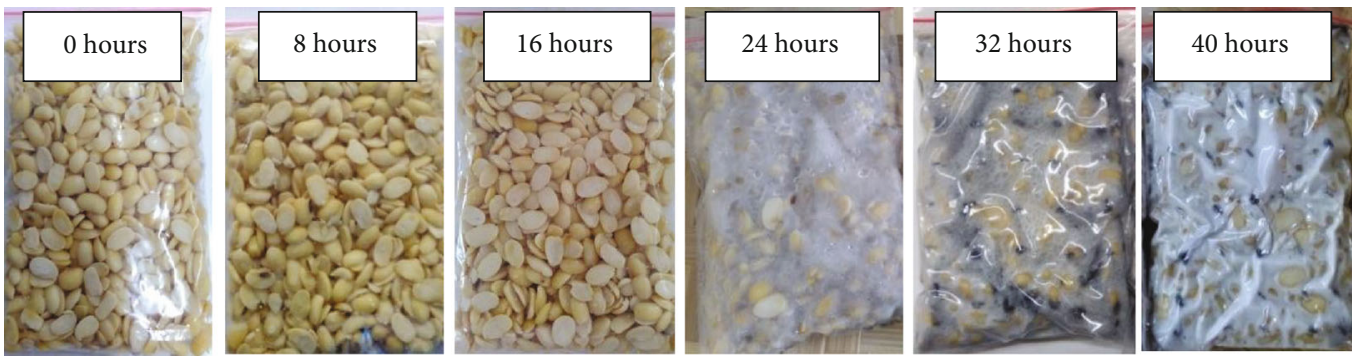

(b)
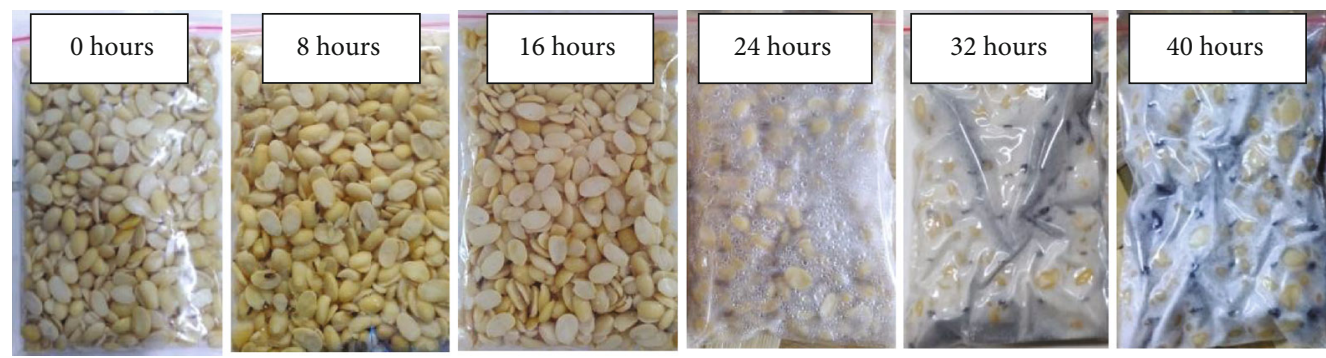

(c)

Figure 2: The appearance of soybeans inoculated with a single culture of S. cerevisiae (a), a single culture of R. oligosporus (b), and mixed culture of both microorganisms (c) during tempeh fermentation.

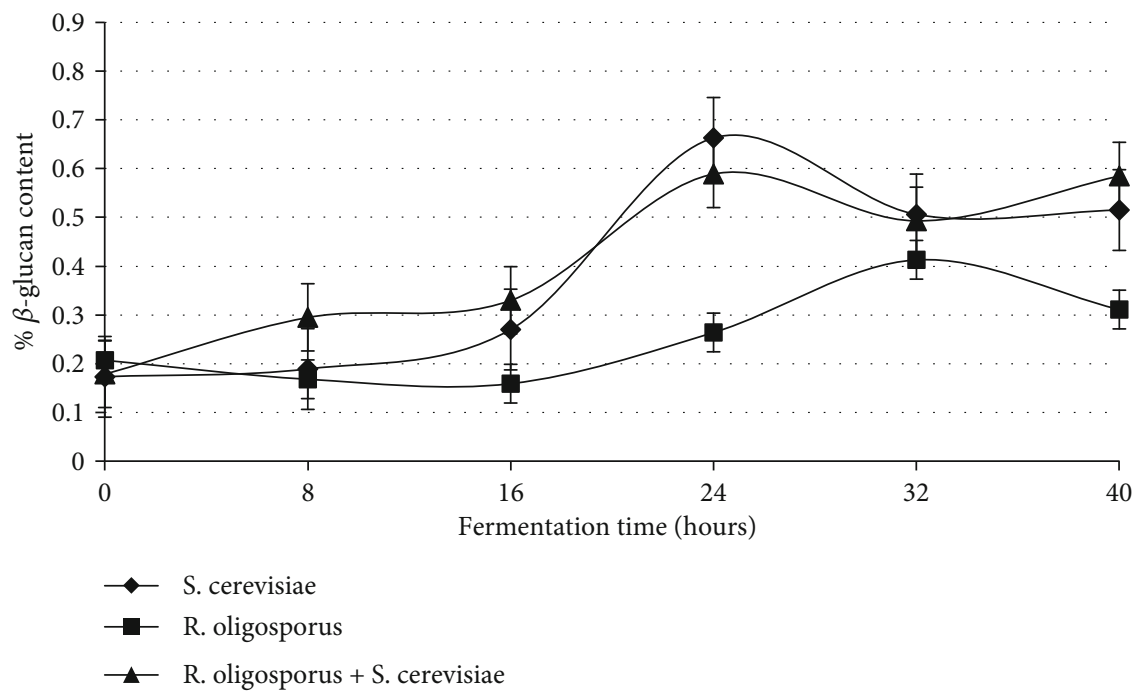

FIgURE 3: The $\beta$-glucan content of soybeans fermented using three kinds of starter culture.

content of tempeh was higher $(0.05 \% w / w)$, compared to that without inoculum. Soybeans inoculated by $S$. cerevisiae and mixed inoculums produced higher $\beta$-glucans in tempeh compared to soybeans without inoculums.
$\beta$-Glucan can be taken from the $S$. cerevisiae cell wall by alkaline extraction, but further purification is needed [21]. The commercial tempeh inoculum contains not only $R$. oligosporus but also other microorganisms and fillers such as 


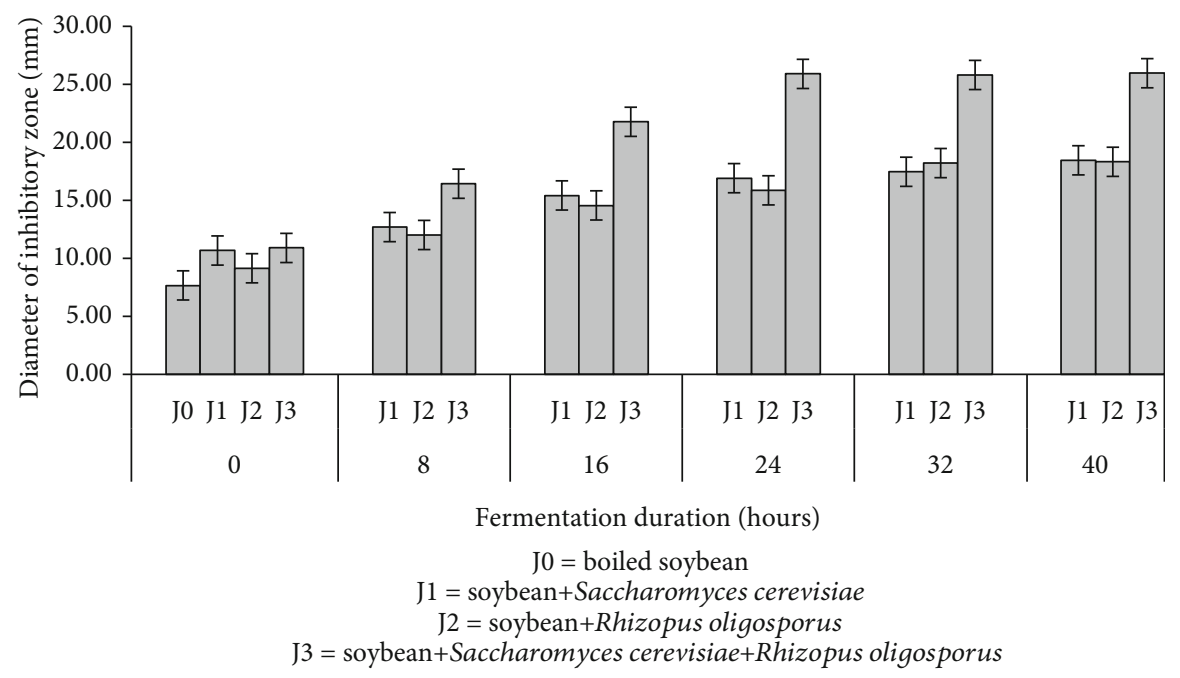

Figure 4: Antibacterial activities of soybeans inoculated by a culture of Saccharomyces cerevisiae, a culture of Rhizopus oligosporus, and a mixed culture of both during tempeh fermentation.

rice flour [22]. The $\beta$-glucan content depends on the addition of $S$. cerevisiae [23] because its cell wall contains $\beta-(1,3)$ - and $\beta$-(1,6)-glucans [11].

Soybeans inoculated with $S$. cerevisiae contained more $\beta$ glucan than those without $S$. cerevisiae (Figure 3 ). These results agreed with Thontowi et al. [24] that the $\beta$-glucan content of $S$. cerevisiae in cultures with $\mathrm{N}$ peptone sources tended to increase along with fermentation time and was relatively constant by the end of fermentation time ( 84 hours). Kusmiati et al. [16] also reported an increase in $\beta$-glucan production using different carbon sources, for example, by utilizing sugar mill waste (molasses) as a fermentation medium. Increased $\beta$ glucan production follows the increasing number of $S$. cerevisiae cells. The formation of $\beta$-glucans continues until S. cerevisiae reaches a stationary growth phase. Kim et al. [25] reported that the $\beta$-glucan content of polysaccharides in black rice bran fermented by $L$. edodes increases with time.

Figure 3 shows that the $\beta$-glucan content of tempeh $(0.578 \%)$ from this study is higher than that from Rizal et al. [26] with $0.076 \%$. Shokri et al. [27] obtained $\beta$-glucan from $S$. cerevisiae cell walls using $\mathrm{NaOH}$ with $27.5 \%$ of $\beta$-glucan, whereas Varelas et al. [28] got $40 \%$ of $\beta$-glucan. Meanwhile, our percentages ranged from $0.05 \%$ to $0.663 \%$, significantly lower than the numbers previously mentioned. This difference was caused by the different methods used to extract $\beta$-glucan. In this study, the $\beta$-glucan content was investigated from the resulting fermented soybean flour, while the $\beta$-glucan content was observed by Shokri et al. [27] and Varelas et al. [28] and was directly isolated from the cell wall of $S$. cerevisiae.

This study showed that the addition of $S$. cerevisiae in the making of tempeh could increase yeast growth and $\beta$-glucan content of tempeh. The highest content of $\beta$-glucan was found in tempeh, which was made by adding a mixed culture of $R$. oligosporus and $S$. cerevisiae inoculums at a fermentation time of 40 hours $(0.578 \% w / w)$ (Figure 3).

3.3. Antimicrobial Activities of Tempeh during Fermentation. Antibacterial activity testing was carried out during the fer- mentation process of soybeans added with various cultures (soybeans $+S$. cerevisiae, soybeans $+R$. oligosporus, and soybeans $+S$. cerevisiae $+R$. oligosporus). In this study, tempeh's antibacterial activity was determined by measuring the inhibitory zone diameter in the form of a clear area around the paper disc. The results showed that tempeh's antibacterial activity increased along with fermentation time for all treatments of starter culture types. The highest inhibitory zone appeared in tempeh fermented by the mixed starter culture at 40 hours of fermentation time, $25.98 \pm 0.56 \mathrm{~mm}$. Meanwhile, the lowest inhibitory area diameter was in soybeans without added inoculum with $7.68 \pm 0.39 \mathrm{~mm}$. The diameters of the tempeh inhibitory area against $E$. coli are different in various cultures and fermentation times (Figure 3 ).

Figure 4 shows that the boiled soybeans without any starter culture addition could still inhibit the growth of $E$. coli with an inhibitory area diameter of $7.68 \pm 0.39 \mathrm{~mm}$. The content of isoflavones in soybeans causes the antibacterial activity of soy. According to Kustyawati [20], antibacterial activity happens because soybeans alone contained isoflavones in the form of genistein $(0.25 \pm 0.60)$ and daidzein $(0.69 \pm 0.20)$. Additionally, according to Dhayakaran et al. [29], soy isoflavones also show antibacterial activity against several pathogens such as Listeria monocytogenes and Pseudomonas aeruginosa.

The addition of soybeans with all three types of starter culture caused an improvement in antibacterial activity during fermentation that continued to increase along with fermentation time. Both $S$. cerevisiae and $R$. oligosporus contribute to increase antibacterial activity during tempeh fermentation. The highest antibacterial activity was in tempeh added with mixed cultures of $S$. cerevisiae and $R$. oligosporus after 40 hours of fermentation. The increase in tempeh antibacterial activity during soybean fermentation by $S$. cerevisiae and $R$. oligosporus was related to tempeh $\beta$ glucan content, which also increased (Figure 3 ). These results are consistent with the research conducted by Rizal et al. [14] that increasing the number of these two microorganisms 
escalates the $\beta$-glucan content, thus increasing the antibacterial activity of tempeh. As stated by Hetland et al. [13], $\beta$-glucans are compounds that are antagonistic to several microorganisms, including bacteria, mold, yeast, and viruses.

The increasing antibacterial activity of tempeh during fermentation is also caused by the increase in the number of soy isoflavones. Kustyawati et al. [6] showed that soybeans added with $S$. cerevisiae and $R$. oligosporus contained daidzein and genistein of approximately 225 and 465, respectively. Increasing the amount of isoflavones increases the inhibitory activity against bacteria because isoflavones act as antimicrobials [30].

Antimicrobial activity is a very important study for food safety and human health. Therefore, it will be very interesting to study the antimicrobial activity of tempeh against other foodborne pathogens.

\section{Conclusions}

The addition of S. cerevisiae and R. oligosporus as mixed inoculums in tempeh fermentation resulted in higher growth of yeast and fungi, $\beta$-glucan formation, and antibacterial activity of tempeh than without the addition of yeast. Therefore, the tempeh can have better functional properties as healthy food due to the health benefits of $\beta$-glucan. In vivo studies need to be done to prove the effect of adding both microorganisms on improving tempeh's functional properties in mice.

\section{Data Availability}

All data generated during and/or analyzed during the current study are not publicly available because the data are still needed to complete a doctorate program of the first author but are available from the corresponding authors on reasonable request.

\section{Disclosure}

There is no involvement of the funder in the design of the experiment; in the collection, analyses, data interpretation, and writing; and in deciding to publish the results.

\section{Conflicts of Interest}

All authors declare no conflict of interest.

\section{Acknowledgments}

Our deepest gratitude goes to Fatimah and Lia Dahlia Pratiwi, alumnae of the Department of Agricultural Product Technology, Faculty of Agriculture, University of Lampung, Indonesia, for their assistance and cooperation in conducting this research. We would also like to thank the Integrated Laboratory of the University of Lampung and the Institute for Research and Community Service, University of Lampung, Indonesia, for their contributions to this work, and the Ministry of Research, Technology \& Higher Education, Indonesia.

\section{References}

[1] M. E. Kustyawati, F. Pratama, D. Saputra, and A. Wijaya, "The modification of color, texture, and aroma of tempe processed with supercritical carbon dioxide," Jurnal Teknologi dan Industri Pangan, vol. 25, no. 2, pp. 168-175, 2014.

[2] D. K. O'Toole, "Non-wheat foods: soy-based fermented foods," Reference Module in Food Sciences, vol. 6, pp. 174-185, 2016.

[3] S. H. Bintari, N. S. Widyastiti, N. D. Putriningt, R. Hapsari, and K. Nugraheni, "Development and properties of tegurt, a yogurt-like tempe product," Pakistan Journal of Nutrition, vol. 16, no. 4, pp. 221-226, 2017.

[4] M. J. R. Nout and J. L. Kiers, “Tempe fermentation, innovation and functionality: update into the third millenium," Journal of Applied Microbiology, vol. 98, no. 4, pp. 789-805, 2005.

[5] R. Triwibowo, "Chemical study of stakiosa and essential fatty acids in soybean tempeh (Glycine max) during the fermentation process," Universitas Sebelas Maret, Surakarta, Indonesia, 2011.

[6] M. E. Kustyawati, Subeki, Murhadi, S. Rizal, and P. Astuti, "Vitamin $\mathrm{B}_{12}$ production in soybean fermentation for tempeh," AIMS Agriculture and Food, vol. 5, no. 2, pp. 262-271, 2020.

[7] C. A. Seumahu, A. Suwanto, I. Rusmana, and D. D. Solihin, "Bacterial and fungal communities in tempeh as reveal by amplified ribosomal intergenic sequence analysis," Hayati Journal of Biosciences, vol. 20, no. 2, pp. 65-71, 2013.

[8] Efriwati, A. Suwanto, G. Rahayu, and L. Nuraida, "Population dynamics of yeasts and lactic acid bacteria (LAB) during tempeh production," Hayati Journal of Biosciences, vol. 20, no. 2, pp. 57-64, 2013.

[9] M. E. Kustyawati, O. Nawansih, and S. Nurdjannah, "Profile of aroma compounds and acceptability of modified tempeh," International Food Research Journal, vol. 2, pp. 734-740, 2016.

[10] N. Pengkumsri, B. S. Sivamaruthi, S. Sirilun et al., "Extraction of B-glucan from Saccharomyces cerevisiae: comparison of different extraction methods and in vivo assessment of immunomodulatory effect in mice," Food Science and Technology, vol. 37, no. 1, pp. 124-130, 2017.

[11] M. Naruemon, S. Romanee, P. Cheunjit, H. Xiao, L. A. McLandsborough, and M. Pawadee, "Influence of additives on Saccharomyces cerevisiae $\beta$-glucan production," International Food Research Journal, vol. 20, pp. 1953-1959, 2013.

[12] M. Del Cornò, S. Gessani, and L. Conti, "Shaping the innate immune response by dietary glucans: any role in the control of cancer?," Cancers, vol. 12, no. 1, p. 155, 2020.

[13] G. Hetland, E. Johnson, D. M. Eide, B. Grinde, A. B. C. Samuelsen, and H. G. Wiker, "Antimicrobial effects of $\beta$-glucans and pectin and of the Agaricus blazei based mushroom extract, Ando San ${ }^{\mathrm{TM}}$. Examples of mouse models for pneumococcal, fecal bacterial, and mycobacterial infections.," in Microbial Pathogens and Strategies for Combating Them: Science, Technology and Education, A. Méndez-Vilas, Ed., pp. 889-898, Formatex, 2013.

[14] S. Rizal, Murhadi, M. E. Kustyawati, and U. Hasanudin, "Growth optimization of Saccharomyces cerevisiae and Rhizopus oligosporus during fermentation to produce tempeh with high $\beta$-glucan content," Biodiversitas Journal of Biological Diversity, vol. 21, no. 6, pp. 2667-2673, 2020.

[15] M. R. Sugoro and Pikoli, "Pertumbuhan khamir pada tapioka iradiasi," A Scientific Journal for The Applications of Isotopes and Radiation, vol. 2, 2006. 
[16] Kusmiati, A. Thontowi, and S. Nuswantara, "Effect of the different carbon sources on $\beta$-glukan production by Saccharomyces cerevisiae on lift water fermenters," Jurnal Natur Indonesia, vol. 3, pp. 138-145, 2011.

[17] S. Ishmayana, A. S. Djajasoepana, S. D. Rachman, and A. Safari, "Fermentation performance of Saccharomyces cerevisiae yeast in VHG media with concentration variation of yeast extract as a nitrogen source for bioethanol production," Padjadjaran University, Bandung, Indonesia, 2012.

[18] K. Kavanagh, Fungi Biology and Applications, John Wiley and Sons Ltd, 2005.

[19] S. K. Wahono, E. Damayanti, T. R. Vita, I. Evi, and Sadyastuti, "Saccharomyces cerevisiae growth rate in the fermentation process of formation of bioethanol from sorghum seeds (Sorghum bicolor L.)," in Proceedings of National Seminar on Chemical Engineering and Processes, p. D04, Semarang, Indonesia, 2011.

[20] M. E. Kustyawati, "Study on the role of yeast in tempeh production," Jurnal Agritech, vol. 29, pp. 64-70, 2009.

[21] A. Javmen, S. Grigiškis, and R. Gliebute, “ $\beta$-Glucan extraction from Saccharomyces cerevisiae yeast using Actinomyces rutgersensis 88 yeast lyzing enzymatic complex," Biologija, vol. 58, no. 2, 2012.

[22] W. Sukardi and I. Purwaningsih, "The trial of the use of tempeh inoculums from mold Rhizopus oryzae with rice and cassava flour substrate in the tempeh production unit of Sanan Kodya Malang," Jurnal Teknologi Pertanian, vol. 9, pp. 207215, 2008.

[23] A. Kusmiati, S. R. Tamat, S. Nuswantara, and N. Isnaini, "Production and determination of $\beta$-glucan levels from three Saccharomyces cerevisiae strains in molasses containing media," Jurnal Ilmu Kefarmasian Indonesia, vol. 5, pp. 7-16, 2007.

[24] A. Thontowi, Kusmiati, and S. Nuswantara, "Glucan production of Saccharomyces cerevisiae in medium with different nitrogen sources in air-lift fermentor," Biodiversitas, Journal of Biological Diversity, vol. 8, no. 4, pp. 253-256, 2007.

[25] S. P. Kim, S. O. Park, S. J. Lee, S. H. Nam, and M. Friedman, “A polysaccharide isolated from the liquid culture of Lentinus edodes (shiitake) mushroom mycelia containing black rice bran protects mice against salmonellosis through upregulation of the Th1 immune reaction," Journal of Agricultural and Food Chemistry, vol. 62, no. 11, pp. 2384-2391, 2014.

[26] S. Rizal, M. E. Kustyawati, Murhadi, U. Hasanudin, and Marniza, "Effect of Saccharomyces cerevisiae concentration on the ash levels, protein levels, fat, and beta-glucan content of tempeh," in Proceeding National Seminar of Anniversiry of Universitas Sebelas Maretpp. 96-103, Surakarta, 2018.

[27] H. Shokri, F. Asadi, and A. R. Khosravi, "Isolation of $\beta$-glucan from the cell wall ofSaccharomyces cerevisiae," Natural Product Research, vol. 22, no. 5, pp. 414-421, 2008.

[28] V. Varelas, P. Tataridis, M. Liouni, and E. T. Nerantzis, "Application of different methods for the extraction of yeast $\beta$-glucan," e-Journal of Science \& Technology, vol. 11, 2016.

[29] R. P. A. Dhayakaran, S. Neethirajan, J. Xue, and J. Shi, "Characterization of antimicrobial efficacy of soy isoflavones against pathogenic biofilms," LWT - Food Science and Technology, vol. 63, no. 2, pp. 859-865, 2015.

[30] D. E. P. Mambang, Rosidah, and D. Suryanto, “Antibacterial activity of tempe extract against Bacillus subtilis and Staphylococcus aureus bacteria," Jurnal Teknologi dan Industri Pangan, vol. 25, pp. 115-118, 2014. 